\title{
Socially acceptable urban agriculture businesses
}

\author{
Kathrin Specht $^{1} \cdot$ Thomas Weith $^{1} \cdot$ Kristin Swoboda $^{1} \cdot$ Rosemarie Siebert $^{1}$
}

Accepted: 27 January 2016 / Published online: 22 February 2016

(C) INRA and Springer-Verlag France 2016

\begin{abstract}
The rise of successful entrepreneurs in urban agriculture has attracted global interest. Here, we hypothesized that societal preferences and the acceptability of urban agriculture projects and products are ruling the success or failure of urban agriculture businesses. We surveyed 386 urban participants in Berlin, Germany, to identify general preferences for the productive use of urban space, the acceptance of different urban agriculture forms, and demands and expectations regarding urban agriculture products. The results show first that more than $80 \%$ of the respondents preferred having accessible systems such as public green spaces, intercultural gardens, and rooftop gardens. Indeed, land uses that do not provide accessibility such as meadows, aquaponic farms, or intensive agricultural and horticultural landscapes showed lower acceptance, of less than $40 \%$. Second, $60 \%$ of participants expressed acceptance of rooftop farming, agriculture in the urban fringe, or in inner-city brownfields, whereas $65 \%$ rejected to have agriculture in multi-story buildings, agroparks, or aquaponic farms. Third, more than $50 \%$ are willing to buy horticultural products, but they reject products from intensive production systems and animal-farming mechanisms, with more than $70 \%$ rejection for animal products. Overall, this is the first study to investigate entrepreneurial urban agriculture possibilities from the perspective of potential consumers. The main insight is that the highest degree of acceptance is reached for multifunctional urban agriculture that combines commercial with ecological and social goals.
\end{abstract}

Kathrin Specht specht@zalf.de

1 Leibniz Centre for Agricultural Landscape Research, Institute of Socio-Economics, Eberswalder Strasse 84, Müncheberg, Germany
As a consequence, projects that are purely production-driven or technologically intensive are more likely to be rejected.

Keywords Urban farming - Business models · Consumers . Land-use conflicts · Production systems · Preferences · Acceptance

\section{Introduction}

With modern cities generally relying on resource imports, the food system involves extensive transportation routes and high-energy requirements for the storing, cooling, and packaging of agricultural products. Urban agriculture has been acknowledged as a strategy for spatially and temporarily reconnecting food production, waste disposal, and consumption to strengthen future city resilience and self-reliance and to improve city capacity to adapt to climate change (De Zeeuw et al. 2011). Although cities to date have largely been deemed "consumptive," new approaches promote the notion of converting cities into "productive" systems. Scholars envision the "edible city" and hypothesize about the incorporation of interlinked "Continuous Productive Urban Landscapes (CPUL)" into cities as an essential element of urban infrastructure (Bohn and Viljoen 2010). The movement to design increasingly dense cities around sustainable food infrastructures has reached a point at which the qualities of "urban" and "rural" areas have merged (Torreggiani et al. 2012).

Mougeot (2001) defines urban agriculture as "an industry located within or on the fringe of a town, city or metropolis, which grows or raises, processes, and distributes a diversity of food and non-food products (...).”

Such practices range from family gardening and community-based farming to commercial flagship projects that use sophisticated technologies (Opitz et al. 2015) 
(Fig. 1). According to Lohrberg and Timpe (2012), the definitions and aims of urban agriculture are multiple and diverse. Beyond food production, urban agriculture provides environmental and social services and supports local economies by a significant direct urban market orientation (Sanyé-Mengual 2015). In the past, urban agriculture has often been discussed as a solution to the global challenges posed by urban population growth and climate change (Despommier 2010; De Zeeuw et al. 2011; FAO 2008). Recently, the emergence of successful entrepreneurs in the field of urban agriculture has attracted the interest of practitioners who aim to emulate urban agriculture practices. This interest has opened a new field of debate, and urban agriculture has been increasingly addressed in terms of new business models and (social) entrepreneurship by policymakers, researchers, and local and global stakeholders (Lohrberg and Timpe 2012; Sanyé-Mengual 2015; Specht et al. 2015a).

It is estimated that approximately $25-30 \%$ urban dwellers are involved in the agro-food sector worldwide (Orsini et al. 2013). Reflecting upon the scholarly debate on the economic dimension of urban agriculture, discussions focusing on urban agriculture have covered a wide range of topics from subsistence farming to large-scale farming. Urban agriculture study objectives and scopes vary depending on the geographical context. Three major fields of study dominate the international literature. The largest body of research addresses urban agriculture in emerging cities of the global south (Orsini et al. 2013). Here, urban agriculture takes on various forms from subsistence farming dedicated to family nutrition and micro-level enterprise to large urban agriculture business operations. In brief, studies that address economic urban agriculture activities in the global south have revealed that one major motivation is to increase food security levels and health conditions while generating family income (Hamilton et al. 2014; Orsini et al. 2013; Poulsen et al. 2015). Urban agriculture serves as an important strategy for urban survival and foodsource diversification (De Zeeuw et al. 2011; FAO 2008). In the well-described case of Cuba, urban agriculture played an essential role in ensuring food security during the time of blockade (Altieri et al. 1999).

The second group of studies addresses urban agriculture in cities of the global north that have faced periods of population loss or economic decline (i.e., "shrinking cities"). Here, activists, NGOs, local governments, and social entrepreneurs have established urban farms on vacant land to maintain the basic provision of fresh food (Opitz et al. 2015). The "food desert" phenomenon has been well documented in the context of US cities, particularly for those "rustbelt cities" (e.g., Detroit) that have experienced economic depressions and population losses in recent decades. In these cases, urban agriculture as an economic activity was reactivated or introduced in cities as a reaction to this crisis (McClintock 2010; Mok et al. 2014) and is therefore of particular relevance to low-income communities with limited food access. As in the USA, comparable developments are emerging in shrinking cities throughout Europe and particularly in countries affected by the recent economic crisis, such as Greece and Portugal (Anthopoulou et al. 2013).

A third group of studies addresses the potential for largescale food production in closed systems and controlled environment agriculture (CEA) (e.g., indoor farms, plant factories, and greenhouses), thus exploring the use of technologically advanced solutions for urban agriculture. Although application of the initial idea of "vertical farming" proposed by Despommier (2010) is still at the pilot stage, some lessfuturistic concepts (such as rooftop greenhouses or plant factories) have already been put into practice. This branch of scholarship focuses geographically on Asian megacities and on the Gulf States. Here, urban agriculture activities are highly market-oriented. In some cases, the motivation is to overcome import dependencies (e.g., in Singapore, which is largely reliant on food imports (Astee and Kishnani 2010)). In some places, consumers trust the quality and safety of products from plant factories or CEA more than products produced via
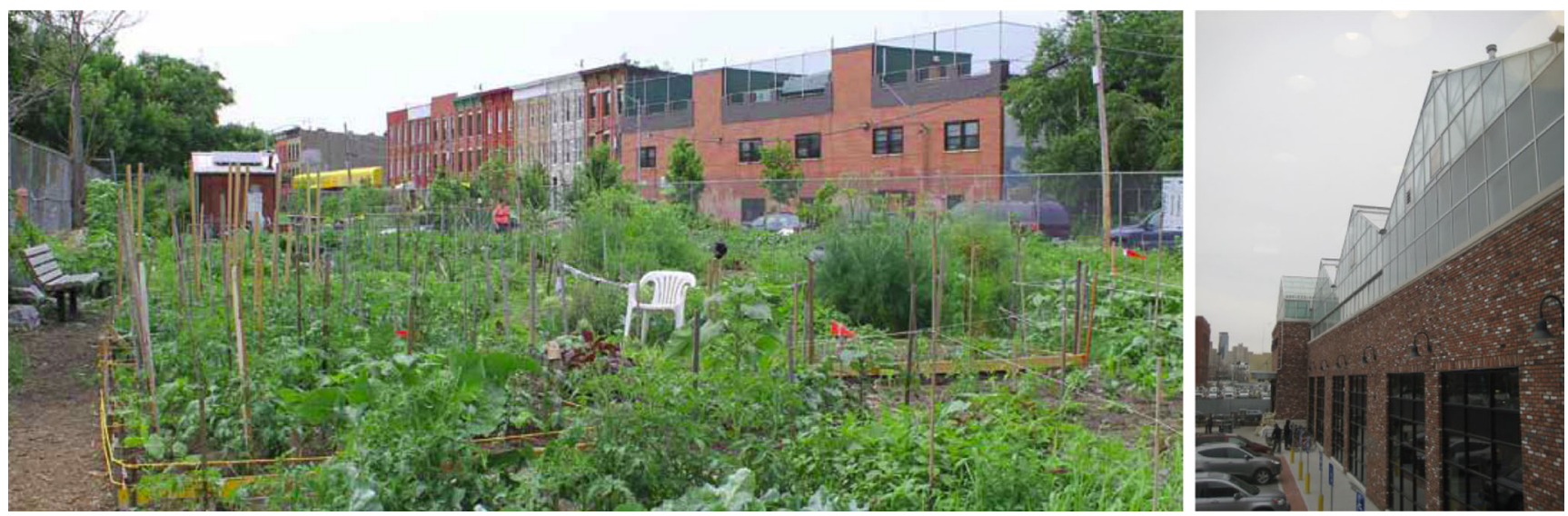

Fig. 1 Urban agriculture can take many forms from community gardens to commercial rooftop greenhouses. Phoenix Community Garden (left, picture by I. Opitz 2012) and Gotham Greens commercial rooftop greenhouse (right, picture by K. Specht 2014) in NYC, USA. UA urban agriculture 
conventional agri-business. For other cities (e.g., desert cities such as Dubai), closed systems save water resources, which serve as a limiting factor. According to Caplow (2009), each hectare of a recirculating hydroponic greenhouse can replace 10 ha of land while saving 75,000 tons of fresh water/year, which is a promising prospect for areas with arable land or water deficiencies.

The consideration of urban agriculture as an entrepreneurial activity applied in other cities of the global north (i.e., cities unaffected by economic crisis) has largely been neglected, especially in Europe. Numerous successful, commercial urban agriculture projects in the USA and Canada have demonstrated their economic viability (Kaufman and Bailkey 2000). Well-known examples from North America are the rooftop farms of "Gotham Greens" (www.gothamgreens.com) or "Lufa Farms" (www.lufa.com). To date, several successful examples of entrepreneurial urban agriculture exist in Europe as well, although opportunities for entrepreneurial urban agriculture in Europe have only been addressed as a peripheral issue.

In the case of Europe, existing studies focus on the technological feasibility or sustainability assessment of specific new forms of urban agriculture, such as rooftop gardens or rooftop greenhouses (Cerón-Palma et al. 2012; Specht et al. 2014; Thomaier et al. 2015). Others estimate the general potentials and problems associated with urban horticulture (Eigenbrod and Gruda 2014), the urban agriculture effects on the environment (Sanyé-Mengual et al. 2013, 2015a, b), and the effect of urban agriculture on specific issues, including health issues (Säumel et al. 2012; Antisari et al. 2015). Particularly for northern Europe, urban agriculture has largely been investigated in relation to its social functions, and it has been proposed that urban agriculture as a "hobby" boosts quality of life, leisure, and community building. Additionally, urban agriculture has been addressed as an element of green urban infrastructure that can fulfill several ecological and climatic functions and that can contribute to "greening the city." However, recent studies of European cities have revealed that urban agriculture can prove relevant for food provision in terms of production quality and quantity (Orsini et al. 2014; Pourias et al. 2015) while generating new market options. Issues of "entrepreneurship" and of real "agronomic productivity" are now attracting attention.

Although scholars have begun to address the abovementioned issues within the field of entrepreneurial urban agriculture, very few studies have investigated societal or potential consumer views on urban agriculture. We assume that societal and consumer preferences and acceptance of urban agriculture projects and products represent important keystones for the successful implementation of future agronomic businesses in urban agriculture. For Europe, questions regarding the social acceptability of urban agriculture have only been addressed as major research objectives in the cases of
Barcelona and Berlin (Sanyé-Mengual et al. 2015c; Schulz et al. 2013; Specht et al. 2015a, b). These studies showed that stakeholders associate potential benefits with urban agriculture but also detect numerous risks and uncertainties. A report by de Wilt and Dobbelaar (2005) clearly illustrates how a planned "Agropark" project in the Netherlands failed due to public averseness and active resistance from residents and the media.

The social acceptance and preferences of potential consumers are decisive factors for the success or failure of an entrepreneurial business. We hypothesize that some attributes related to urban agriculture may lead to the rejection of particular projects and products and that it will not be clear to potential project initiators whether a project or its products will be "accepted" by potential consumers (see also Section 2.1). This issue has not been sufficiently addressed in the scholarly debate. In our study, we aim to address this research gap by focusing on the perspectives of city inhabitants as potential consumers and by examining their preferences and levels of urban agriculture acceptance in the context of Berlin. We address the following specific objectives herein:

- What are the general preferences for the urban land use/ utilization of urban space in Berlin?

- What is the social acceptability of different forms, production systems, and orientations of urban agriculture?

- What are the demands for and expectations of urban agriculture products?

Based on these objectives, we discuss potential opportunities and limitations of entrepreneurial urban agriculture. We focus on potential consumers' preferences and their acceptance or rejection of particular urban agriculture forms and products.

\section{Materials and methods}

\subsection{Analytical framework and levels of investigation}

Urban agriculture activities can vary in terms of spatial setting, production capacity, and economic and entrepreneurial potential. We consider the overall preferences and acceptance of different urban agriculture forms and products as an important framing condition that may strongly influence the diffusion and entrepreneurial success or failure of new forms of urban agriculture. According to Lucke (1995), innovation is not only an economic mechanism or technological process but also a social phenomenon that reveals the demands of both individuals and society as a whole. Therefore, innovations are highly related to their societal framing conditions and their success or failure depends on the societal willingness to "accept" novel ideas. In this early innovation phase, the social acceptability of 
urban agriculture will become relevant to the successful introduction and implementation of urban agriculture in urban social and spatial environments. Previous studies have revealed that a lack of acceptance by relevant stakeholders or targeted communities can be a major limiting factor in the implementation of urban agriculture (Poulsen et al. 2014; SanyéMengual 2015c; Specht et al. 2015b) Our hypothesis is that some characteristics of urban food production may provoke negative responses from potential consumers and that, for a project initiator, whether a project or the envisaged products for sale will be approved by the addressed consumers is uncertain. In the event of low acceptance by the targeted group, products may not be purchased and projects might fail. Therefore, the introduction of alternative urban land uses and new urban agriculture systems and products in the field of urban agriculture may entail risks for those who wish to develop, finance, or implement urban agriculture innovations. It is essential for policymakers to understand this process when establishing a legal framework for urban agriculture development.

Our analysis includes three levels of investigation (Fig. 2). We analyze the preferences for and acceptance of (i) general urban land use, (ii) different urban agriculture forms, and (iii) urban agriculture products (Fig. 2).

The first level of investigation addresses general preferences for urban land use and the utilization of urban space. Open spaces can be dedicated to different uses and include both private to public purposes. Urban agriculture activities may therefore either complement or compete with other forms of land use.

Second, we analyze preferences for urban agriculture that vary in regard to organization, production system configuration, and market potential. We differentiate between the following forms (partly adapted from Opitz et al. 2015):

1. Backyard gardens are predominantly private gardens, and similar to balconies associated with residential food production and self-consumption, they generally have no market orientation.

2. Brownfields and greenspaces are frequently used for urban agriculture in public spaces and often take the form of community gardening. Community gardens, managed by self-organized initiatives or neighborhood groups, produce food for the personal or common benefit of garden members. They are either dedicated to self-consumption or are organized as small businesses/social enterprises.

3. Rooftop farms can be organized collectively or privately. They range from community rooftop gardens to private businesses that establish rooftop farms (i.e., open or closed systems) as flagship enterprises.

4. Pick your own (PYO) is a variation of direct marketing. A farmer prepares a plot and plants a variety of agricultural and horticultural products. Plots are either opened to the public for special picking events or are rented by a consumer for one season, whereby the consumer assumes responsibility for further maintenance and harvesting.

5. Urban agriculture on the urban fringe refers to farm units positioned along town boundaries that operate intensive semi-commercial or fully commercial farms to grow vegetables and other horticultural products, raise chickens and other livestock, and produce milk and eggs. This form of production is largely market-oriented.

6. In aquaponic farms, two production systems are combined: aquaculture and hydroponics. These systems can range in size and complexity but are typically organized as market-oriented businesses.

7. Agroparks are large production and processing units that are positioned close together so that they can make collective use of one another's by-products (de Wilt and Dobbelaar 2005). This system has a strong market orientation.

8. Vertical farming involves cultivating plants or animal life within skyscrapers or on vertically inclined surfaces (Despommier 2010). Vertical farming efforts involve large-scale food production with a strong market orientation.

Third, we examine a variety of potential urban agriculture products and their associated attributes. Urban agriculture may be able to generate a wide range of products that may either meet or fall short of potential consumer expectations and demands.

\subsection{Urban agriculture activities in Berlin (Germany)}

Berlin, the German capital, has a population of 3.5 million people and is the second most populous city in the EU (as defined by population within city limits). Urban agriculture has a long historic tradition in Berlin that is rooted in times of industrialization and rapid urban growth that occurred throughout the nineteenth century. Inner-city gardens were established to improve the health and self-sufficiency of inhabitants, particularly the working class and poor. Later, urban gardens helped sustain the population through the two world wars and in times of economic crisis and limited food access. Currently, 3000 ha covering more than 73,000 lots fall under the official planning code of urban allotment gardens in Berlin, i.e., the so-called "Schrebergarten" (weblink \#1).

In recent years, new types of urban agriculture initiatives and operators have emerged with the intention to plan and implement projects throughout the city. These entities range from voluntary associations for social enterprises to private companies. In contrast to traditional, home food gardens, they are driven by communities or companies as part of the social economy or as new business models. Among the $>100$ community gardens situated in Berlin, initiatives such as 


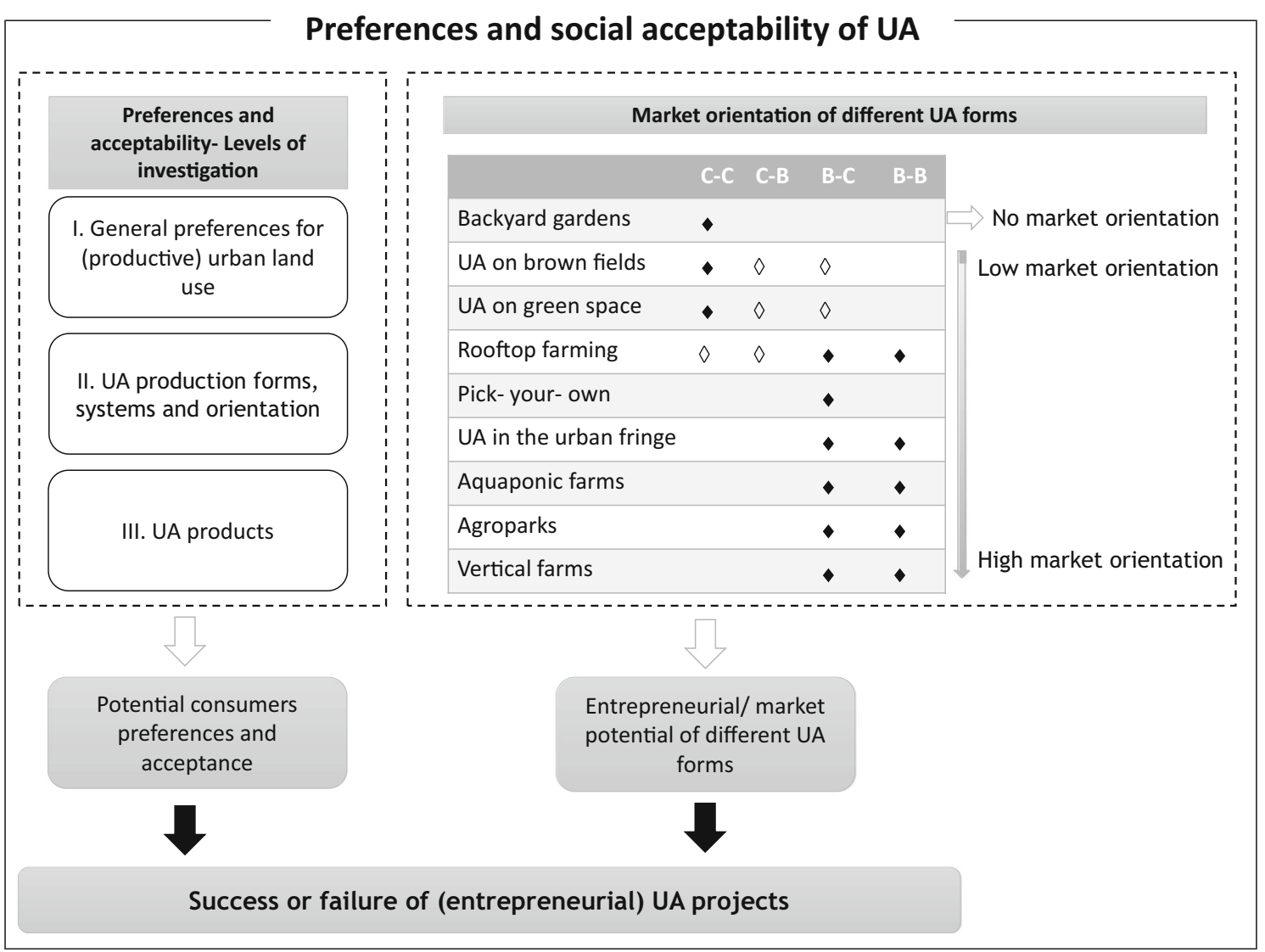

Fig. 2 Analytical framework for the investigation of potential consumer preferences for and acceptance of urban agriculture (UA). Modes of market orientation of different urban agriculture forms based on van der Schans (2015): $C$ - $C$ indicates consumer to consumer, $C-B$ indicates consumer to business, $B-C$ indicates business to consumer, $B-B$ indicates business to business, closed diamonds indicate typical business model, and open diamonds indicate possible business model
"Himmelbeet" (weblink \#2), "Prinzessinnengarten" (weblink \#3), and the gardens of the former inner-city airport Tempelhof (e.g., "Allmende Kontor" (weblink \#4)) are wellknown examples. Whereas some produce food for individual use, others act as (social) enterprises by selling food and providing other services (e.g., offering rental space for public or private workshops and events, operating an associated café, and offering products such as T-shirts).

The Federal State of Brandenburg that surrounds Berlin is home to numerous producers of agricultural and horticultural products that are marketed in the Berlin metropolitan area. Peri-urban farmers provide a large share of products delivered to urban consumers via direct marketing or regular distribution channels (retailers). Apart from traditional farming models, community-supported agriculture (CSA) and Pick your own (PYO) initiatives are experiencing increasing demand, and an increasing number of these businesses have been initiated, particularly along the urban fringe (e.g., "Meine Ernte" (weblink \#5), "Bauerngarten" (weblink \#6), and "Speisegut" (weblink \#7)). Regional agricultural products (from Brandenburg) are increasingly requested by Berlin consumers. A recent study on consumer behaviors in Germany revealed that $92 \%$ of German consumers prefer to purchase regional products. The demand for regional products is steadily increasing, particularly among urban consumers of higher education and income levels (weblink \#8). Additionally, consumers desire improved transparency in food production and more information on food origins. In consideration of these trends, professional urban agriculture may also help to meet the demands of Berlin's consumers.

A different category of companies promotes technological innovations in urban agriculture. Several rooftop farming pilot projects have been established as experimental cases for research to test new applications of urban agriculture in Berlin (e.g., "Efficient City Farming (ECF)" (weblink \#9) or "topfarmer" (weblink \#10) business entrepreneurs). Other entities focus on the further development of technologies that use aquaponic or building-integrated farming (e.g., "Tomatenfisch" (weblink \#11), which explores hydroponic techniques, and "Watergy" (weblink \#12), which tests new types of building-related greenhouses to improve energy efficiency levels through solar thermal-energy storage, water recycling, and desalination).

This growing number of urban agriculture projects is accompanied by increasing public and political awareness and 
media attention. Consequently, we considered Berlin as a suitable case for our study.

\subsection{Methods and empirical basis}

To investigate consumer preferences and the social acceptability of urban agriculture in Berlin, we conducted research based on the following methods and empirical frameworks:

1. Case study selection-Berlin (Germany) was selected as a single case study (Yin 2009). As described in Section 2.2, urban agriculture has a long tradition in Berlin and is both well established and growing in popularity.

2. Survey content-Our survey included 17 questions and was divided into five topical sections. It included questions on (1) demographic characteristics and previous urban agriculture knowledge, (2) general urban land use/ urban space utilization preferences, (3) perceptions of different urban agriculture forms and production systems, (4) urban agriculture product preferences and demands, and (5) perceived potential impacts of urban agriculture at the societal and city levels.

3. Survey execution-The surveys were carried out in January 2012 by students of Humboldt University in Berlin as face-to-face interviews. Each interview took approximately 10 to $30 \mathrm{~min}$. Effort was made to sample a variety of residents. To recruit participants for the survey, the interviewers entered different populated public urban spaces (such as shopping areas, metro stations, and main squares) in different neighborhoods throughout Berlin. The interviewers were instructed to go to areas in the former East and West parts of the city and to interview in districts with above-average incomes and in those with rather low incomes. The interviewees were also instructed to approach participants of different age groups. Potential participants were approached randomly and asked if they were willing to participate in the survey. Participants were selected according to their willingness to partake. The survey can therefore be characterized as an exploratory, non-probability sampling survey. It is thus not considered to be statistically and demographically representative of the residents of Berlin. However, this exploratory approach is appropriate because it offers preliminary insights into a previously unexplored topic. The convenience sampling method allowed us to collect information and basic data and to identify trends without requiring the use of a randomized sample. In the event a participant was not familiar with the presented production systems, the interviewer explained them and provided photos.

4. Empirical basis - The survey was completed by 386 participants. The participant characteristics are provided in Table 1. The survey sample is not representative of the demographics of Berlin residents and is characterized by a high proportion of younger, urban individuals (2040 years); therefore, our results may be considered as biased towards this demographic.

5. Data analysis and interpretation-For data analysis purposes, the survey results were digitized, validated, and interpreted. We used descriptive statistics to summarize the survey results. A selection of the survey results is presented below (Table 1) and discussed with respect to the objectives and analytical framework of the study.

\section{Results and discussion}

\subsection{General preferences for (productive) urban land use}

Urban greenspaces have the potential to play various social, economic, and ecological roles. We assume that visual projections of what a city is supposed to look like and the prioritization of different urban functions will determine the conditions for introducing urban agriculture to urban spaces. Herein, we investigate participant preferences for urban land use and determine whether participants view urban agriculture as a suitable form of urban land use. To obtain insight into the general preferences of participants for urban land use, we asked the participants the following: "Which of the following uses of green and open space would you like to have in your direct living environment?" [Q1]. This question targets general preferences for the use of green and open space (Fig. 3).

The results demonstrate that most of the respondents reported a preference for the uses of green and open space that allow for recreational and leisure activities. More generally, preferred uses of urban spaces involved those that integrate recreational functions while remaining open to the general public or surrounding neighborhood, as can be found in public parks and gardens or in agricultural production sites with events for members of the public (e.g., maize/labyrinth paths, educational trails, or demonstration plots). As in numerous other growing cities, inner-city greenspaces in Berlin are decreasing in number, thereby limiting the number of opportunities the city can offer for outdoor activity and mental restoration (weblink \#13). The priorities identified herein align with general planning principles and strategies. Urban planners that developed guidelines for Berlin and for other European cities envisioned the ideal city as "compact, urban and green" and therefore prioritized inner-city urban development without the consumption of greenspace (weblink \#14).

As most of the surveyed individuals reported appreciation for the use of public greenspace, they may view the integration of productive uses as competing, and this may spur land-use conflicts. The overall level of acceptance was high for those types of production that do not restrict accessibility but rather 


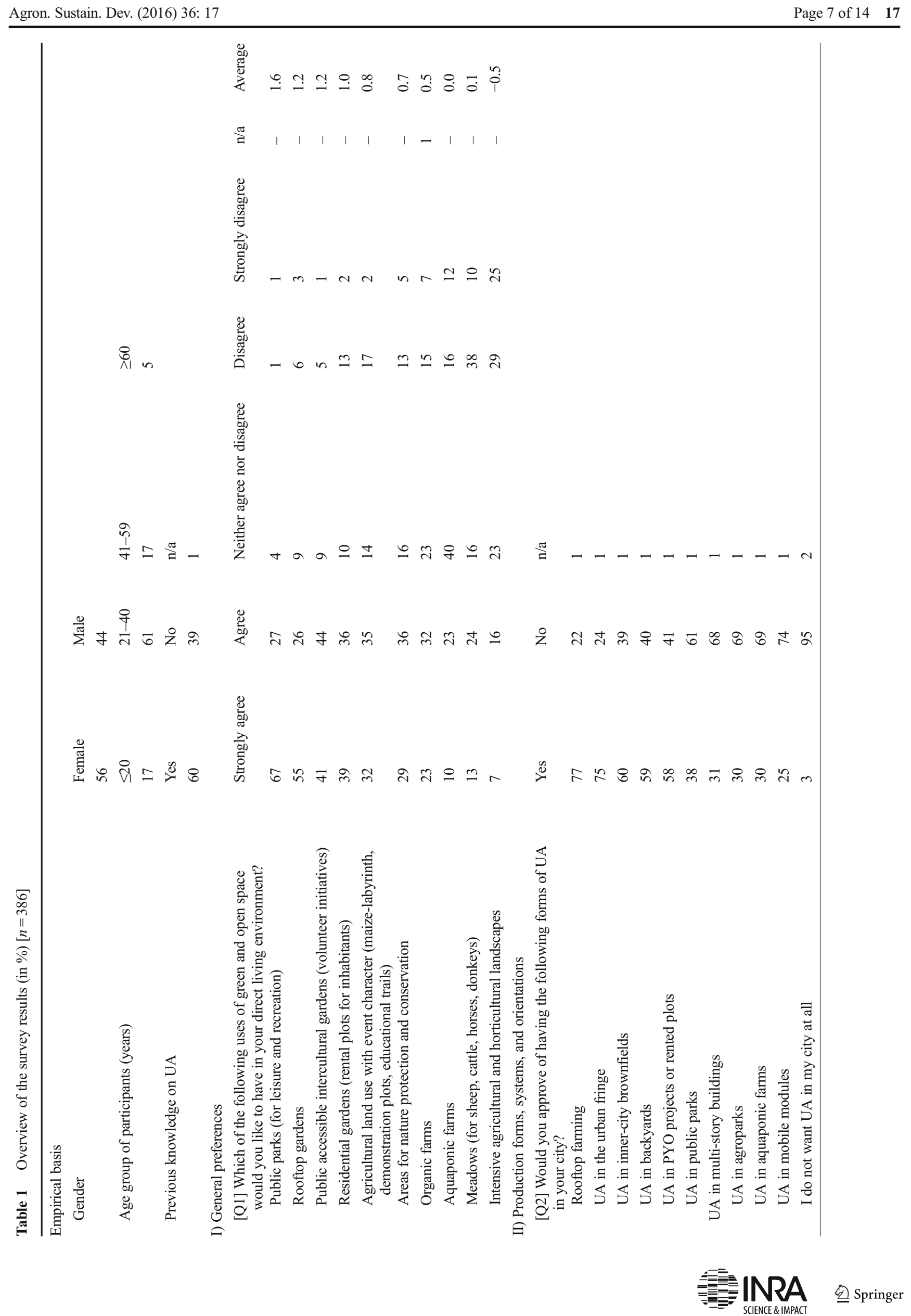




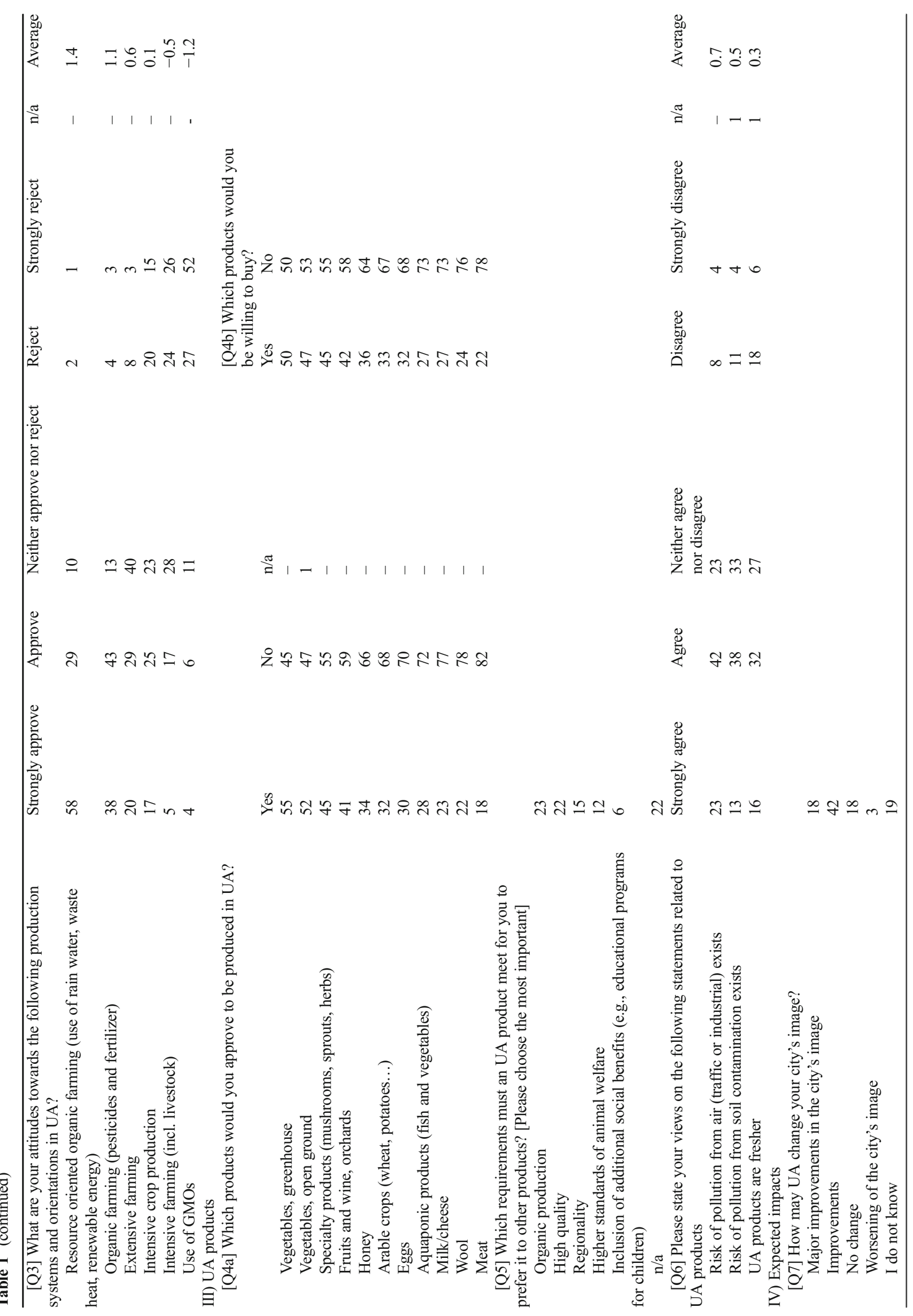


offer opportunities for participation. All options proposed for urban land use that exclude recreational uses show markedly lower levels of acceptance. An exception was land use for "landscape and nature conservation," which shows a high level of acceptance despite potentially decreasing public accessibility. In Germany, areas under the nature conservation act allow only limited use and accessibility. Nature conservation measures are well accepted and appreciated in Germany, a trend that may be attributed to the nation's long history of environmental education (weblink \#15). Professional agricultural or horticultural activities, such as extensive or intensive farming, aquaponic farming, and pasturage activities, show very low levels of agreement among the survey participants. The large number of participants expressing indifference regarding "aquaponic farms" might be explained by a general lack of knowledge about that type of production system.

Unexpectedly, rooftop gardens are highly appreciated. This observation might be because rooftops are generally vast, unused spaces that present opportunities for productive use and because people generally appreciate green areas as recreational spaces. Therefore, urban agriculture activities on rooftops, even if they are dedicated to private or non-public activities, are less often perceived as competing or conflicting forms of land use as are urban agriculture uses in ground-based urban spaces.

The results presented in this section reveal that opportunities for public participation and accessibility play a major role when considering uses of urban spaces for urban agriculture. The levels of these opportunities may limit the implementation of large-scale and commercially driven projects in innercity spaces. A general preference for socially integrated projects has also been reported in previous studies on urban agriculture among stakeholders in Berlin (Specht et al. 2015b). To summarize, the results of the present survey highlight that higher public acceptance can be obtained for projects that have recreational or educational functions and that ensure public accessibility. The exploitation of rooftops for business-oriented urban agriculture activities appears promising as land-use conflicts may not occur or be less severe than those conflicts arising from "on the ground" activities.

\subsection{Preferences for urban agriculture forms, production systems, and production orientations}

Here, we describe the preferences and levels of acceptance of different urban agriculture options ranging from lowly to highly market-oriented projects. The acceptance of feasible forms of urban agriculture is a crucial precondition of their economic success. Therefore, we surveyed participants as to their level of approval of different urban agriculture forms [Q2]. The results reveal that participants hold generally positive views in regard to urban agriculture activities that do not present potential land-use conflicts with other preferred uses 


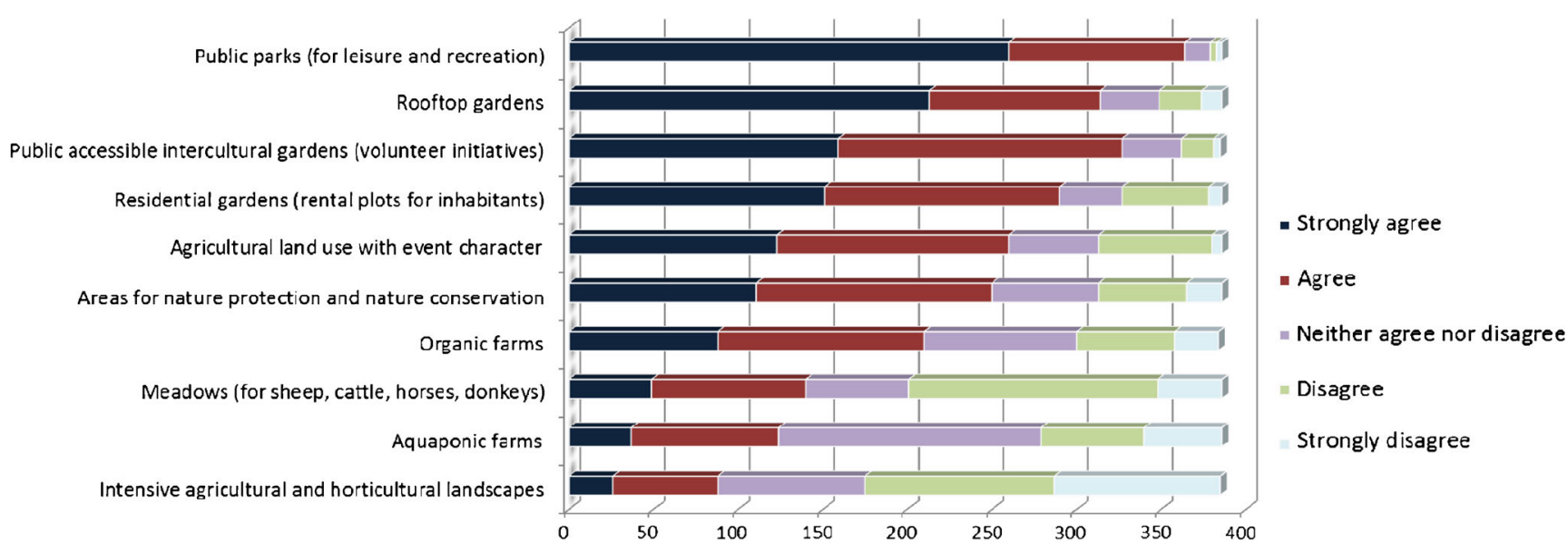

Fig. 3 General preferences for (productive) urban land use in Berlin: [Q1] Which of the following uses of green and open space would you like to have in your direct living environment?

(e.g., rooftop farming is preferred). Furthermore, forms that are consistent with traditional images of agricultural/ horticultural production and that apply low-tech production systems are more likely to be accepted. Urban agriculture on rooftops, along the urban fringe, on brownfields and in backyards shows a high level of acceptance, whereas urban agriculture with connotations of intensive or high-tech agriculture (e.g., agroparks, aquaponic and vertical farming) is less accepted (Fig. 4). These survey outcomes are consistent with the results of previous studies investigating stakeholder perceptions of innovative forms of urban agriculture (SanyéMengual et al. 2015c; Specht et al. 2015b).

Berlin is currently not facing any food security problems, and its inhabitants (being surrounded by highly productive rural land) generally question the need for large-scale urban agriculture (Specht et al. 2015a, b). However, there is a growing demand for local food products, and urban agriculture could complement the existing food system. Comparing these results with the categorization of business models (Fig. 2) reveals that projects that appear promising in terms of market potential are strongly rejected.

To determine participants' views on different production orientations, we asked respondents about their level of acceptance of various potential urban agriculture production orientations (e.g., organic, intensive, or GMO) [Q3]. The results demonstrate that environmentally friendly production orientations, such as organic or extensive production operations, are generally well supported, whereas intensive crop production
Fig. 4 Preferences for different forms of urban agriculture: [Q2] Would you approve of having the following forms of urban agriculture in your city?

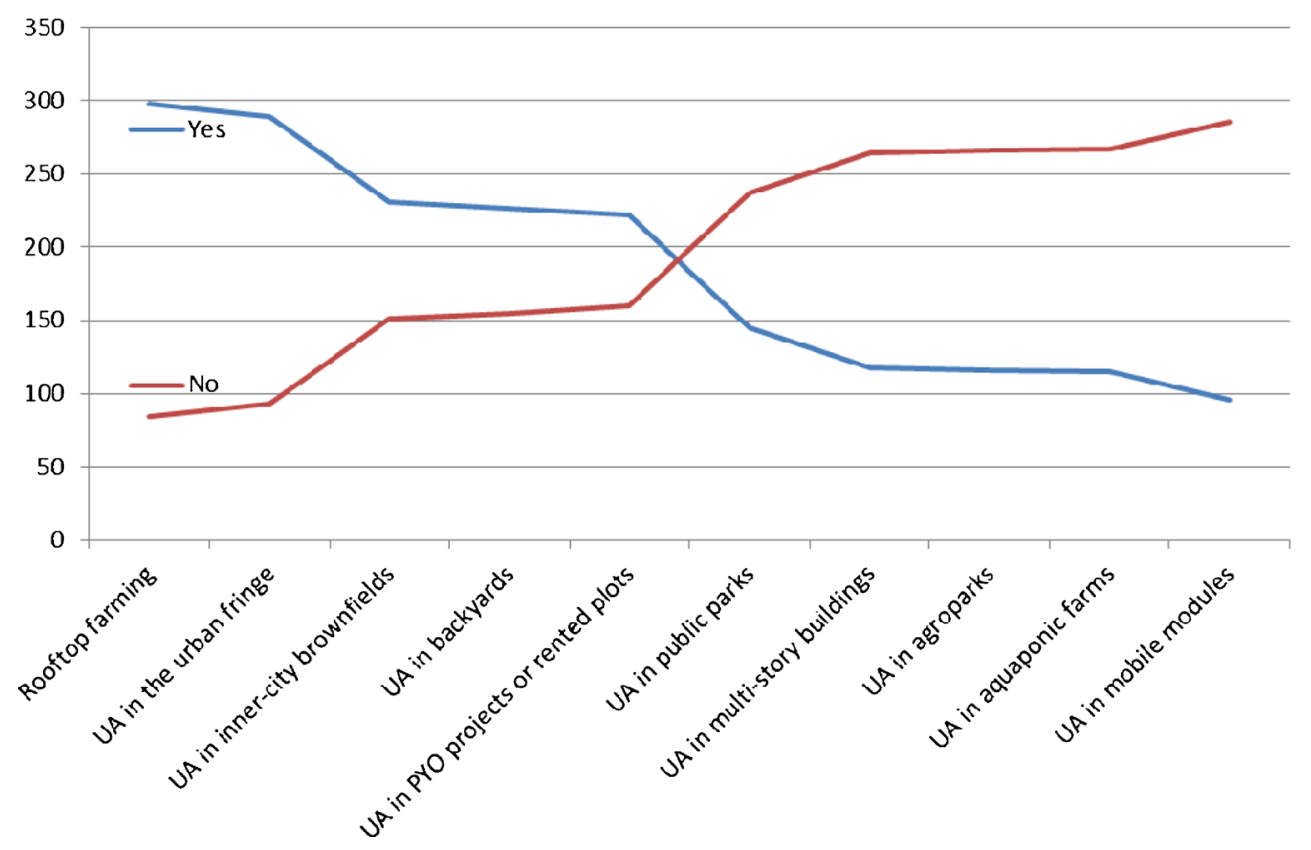


is largely rejected. GMO and intensive production in combination with animal husbandry show particularly low levels of support. These results regarding GMO production are consistent with previous studies from Germany. The German population shows a low acceptance for the use of GMOs, particularly in the food sector (Thiel 2013). The pronounced division of views regarding "resource oriented, organic and extensive" versus "intensive" practices suggests classifications of "good" and "bad" agricultural practice. Our sample was not representative of the German population as it was characterized by a high proportion of young, urban individuals (20-40 years of age) who are generally more amenable to purchasing organic and local products than the average German individual (weblink \#8). Similar to societal views of rural agriculture, preferred practices are those perceived as healthy and safe, whereas practices that are associated with particular risks (such as GMO or intensive animal production) are often rejected in relation to urban agriculture. This phenomenon was observed by de Wilt and Dobbelaar (2005), who described how an agropark proposal in the Netherlands failed due to public resistance. Agroparks are spatial clusters of intensive agricultural production (see de Wilt and Dobbelaar 2005). The authors concluded that many consumers prefer "naturally" produced food and that highly technological production systems may not match consumer preconceptions about food production. Manufacturers and advertisers suggest that agricultural products are "natural" and "traditionally produced," thus reinforcing romantic views of farming. In urban agriculture, producers and consumers are part of the same community, and potential consumers are directly confronted with the production process. Therefore, practices that do not represent idealized images will face greater challenges when performed in urban agriculture than in rural production where they are "out of sight." Consumer proximity to production in urban agriculture would reveal the intensive production methods of which many consumers had previously been unaware.

To summarize, individuals tend to be more receptive towards the introduction of organic, low-tech, and extensive urban food production and are rather critical of production systems and orientations that show high levels of intensity and technology use. Systems that may be more promising from a business perspective (e.g., vertical farming, agropark development, or aquaponic farming) appear to face greater acceptance barriers.

\subsection{Preferences related to potential urban agriculture products}

To identify public preferences for urban agriculture business products, we asked "Which urban-agriculture-produced products would you approve of?" and "Which products would you be willing to buy?" [Q4a; Q4b]. The results illustrate that horticultural products (e.g., vegetables) grown in either open-ground or greenhouse settings received the highest levels of approval and purchase willingness. For all of the other proposed products (e.g., fruits, honey, arable crops), the participants generally did not approve of proposals to grow them in urban areas, responding that they would not want to buy such products. The lowest purchase willingness levels were expressed for animal products (e.g., meat, wool, cheese/milk, fish, and eggs). Low acceptance of urban animal production has also been found in previous studies (de Wit and Dobbelaar 2005; Specht et al. 2015b). Two main reasons were provided for these objections. First, individuals suspect that their quality of life would decrease due to intensified odors and noise. Second, urban environments are perceived as "unnatural" spaces for raising livestock. Although cattle, sheep, and other large farm animals appear to fall outside the paradigm of commercial urban agriculture (Despommier 2010), fowl, pigs, and fish are often proposed for commercial urban agriculture. The fact that these products are met with low consumer acceptance may present barriers for those who wish to establish urban agriculture businesses that involve animal production.

Nevertheless, participants state that they would prefer urban agriculture products to conventional rural products under some conditions. When asked "Which requirements must an urban agriculture product meet for you to prefer it to other products?" [Q5], most answered that they would prefer urban agriculture products to others if the former fulfilled specific criteria, namely, high quality, regionality, organic production, higher standards of animal welfare, or the inclusion of additional social benefits. The results reveal that quality demands for urban agriculture are greater than or equal to the quality demands for rural products. Our results imply that urban agriculture producers must either adhere to very high product standards (e.g., organic) or consider other values that are appreciated by consumers (e.g., provide additional social benefits). In addition, well-considered product marketing and communication, product labeling, and quality certification mechanisms would prove vital to the success of potential urban agriculture enterprises.

High expectations and demands in regard to product quality are attributed to existing fears and associated risks that individuals assign to urban agriculture products [Q6]. The majority of participants agreed that urban agriculture products are superior in terms of "freshness," but most participants discussed the perceived risks of contamination through air pollution and contaminated soil. Scientific uncertainties regarding the health risks of urban food production remain, and these risks are an important focus of future research. Studies have identified some risks that can be avoided through proper management and control mechanisms (e.g., the establishment of minimum distances to main roads, proper washing practices, and the substitution of contaminated soil) (Antisari 
et al. 2015; Säumel et al. 2012). Health risks can also potentially be minimized by establishing a product certification scheme that guarantees low levels of contaminants.

The results presented in this section reveal a higher level of acceptance and willingness to purchase horticultural products over animal products (which are largely rejected). Nevertheless, individuals attribute urban agriculture products with risks and uncertainties; thus, strict controls and proof of product quality (certification) are necessary to counter existing doubts.

\subsection{Perceptions of urban agriculture impacts}

At the end of the survey, participants were asked to estimate the impacts of urban agriculture on urban environments and on quality-of-life measures [Q7; Q8]. In addition to its economic functions, urban agriculture is generally considered to generate additional non-food and non-market goods and to provide multifunctional benefits. Overall, most of the participants expressed that urban agriculture initiatives would help improve the city's image. Only 10 individuals replied that urban agriculture would worsen the city's image. Most agreed that urban agriculture can have positive effects in the following areas: environmental improvement, education, job creation, leisure activity option diversification, community building, and societal views of agriculture. Although these effects have not yet been studied in Berlin, perceptions of positive impacts are reported in other studies that describe similar urban agriculture impacts elsewhere (Anthopoulou et al. 2013; Caplow 2009; Eigenbrod and Gruda 2014; Pourias et al. 2015; Sanyé-Mengual et al. 2013; Specht et al. 2014). It is likely that urban agriculture can similarly offer social and environmental benefits in Berlin.

\subsection{Study limits, study generalizability, and opportunities for further research}

Our study can be understood as a seminal case. As we applied an exploratory, non-probability sampling approach, the results are not representative of the German population as a whole. In addition, our survey was characterized by a disproportionate number of urban, younger (20 to 40 years old) participants. It would be useful to repeat the survey using a larger, more representative sample in Germany or beyond. Future studies that investigate potential consumers' acceptance and preferences can build on our results and use them to generate hypotheses.

For our study, we relied on a single case study. As social acceptability and perception are highly dependent on locally framed conditions and cultural factors, it is necessary to compare our results to other case studies in the future. Regarding the transferability of our study, we assume that comparable results would be found in other spatial contexts with similar characteristics (e.g., in growing cities of the global north that are surrounded by productive agricultural land). Nonetheless, we expect differences from our results if similar studies are conducted in cities that have different characteristics (e.g., cities that are shrinking, import-dependent, or located in deserts). We assume that the perceptions of risks (e.g., regarding technology, soil-less growing, or animal production) differ geographically and culturally.

Future studies could expand on our objectives and investigate how preferences and acceptance variables depend on age, gender, education, or previous knowledge about urban agriculture. In addition, future studies could analyze preferences regarding urban agriculture in competition with other businesses, such as rural producers, or with other sustainable practices (e.g., photovoltaic production in rooftop farming). Evaluating "willingness to pay" in a future survey could provide a quantitative estimation of the acceptance of food products and further details on the competitiveness of UA projects. Furthermore, it could be interesting to include in future surveys questions on general consumption behaviors and values of participants (e.g., perceptions regarding buying organic or local food).

It would be valuable to add a spatial analysis to a study of survey-based acceptance data and evaluate whether preferences for different types of urban agriculture vary among neighborhoods. Some types of urban agriculture might be accepted or rejected depending on the area (e.g., peri-urban, low-density, or high-density neighborhoods).

As our study represents a first attempt to obtain insights into an entirely new research question, the results do not allow us yet to offer general guidelines and recommendations. Once more robust data are available, the next step will be to review the possibilities and instruments for planning, the construction of legal frameworks, and community buy-in to incorporate the consideration of potential consumers and public demands into urban agriculture projects and increase their acceptance.

\section{Conclusions}

We surveyed potential consumers in Berlin to gain insights into their preferences and acceptance of urban agriculture projects and products. This is the first study to investigate the expectations and demands of city inhabitants in regard to urban agriculture. Our results are relevant to those who seek to plan, establish, or finance future urban agriculture projects. Our study revealed that conflicting interests are often present regarding preferences for existing open spaces. In the event of the expansion of urban agricultural areas, land-use conflicts could arise, for example, when urban agriculture activities do not ensure public accessibility. In particular, forms of urban agriculture that are promising in terms of production 
quantities (e.g., agroparks, aquaponic or other large-scale commercial farms) show low levels of acceptance. We assume that these low acceptance levels reflect the high levels of technological and production intensity of these forms. Preferred forms of urban agriculture show lower potential for entrepreneurial innovation, for example, community or home food gardens.

In conclusion, the results of our study suggest that urban agriculture projects that are multifunctional and that combine commercial goals with ecological and social goals can potentially achieve the highest levels of social acceptance, whereas projects that are purely production-driven and technologically intensive will more likely experience rejection. Our results are relevant to the future planning and development of urban agriculture. First, notions of multifunctional space use must be incorporated into concepts and guidelines. Second, the necessity of acquiring acceptance for urban agriculture (e.g., through participation) must be recognized as a precondition for the successful implementation of future projects. The success of future urban agriculture initiatives will be contingent on society acknowledging these forms of urban land use as integral to urban areas.

Acknowledgments This work was supported by the funding from the Federal Ministry of Education and Research, Germany (BMBF) (funding code FKZ 033L004). The Leibniz Centre for Agricultural Landscape Research (ZALF) is institutionally funded by the Federal Ministry of Food and Agriculture (BMEL) and by the Ministry for Science, Research and Culture of the State of Brandenburg (MWFK). We would like to acknowledge Prof. Bokelmann and Nicole Petzke from Humboldt University of Berlin for preparing and conducting the survey. We would also like to thank the survey participants for their cooperation.

\section{References}

Altieri MA, Companioni N, Cañizares K, Murphy C, Rosset P, Bourque M, Nicholls CI (1999) The greening of the "barrios": urban agriculture for food security in Cuba. Agric Hum Values 16:131-140. doi: 10.1023/A: 1007545304561

Anthopoulou T, Partalidou M, Moyssidis M (2013) Emerging municipal garden-allotments in Greece in times of economic crisis: greening the city or combating urban neo-poverty? E-Proceedings of The XXV ESRS Congress. Laboratorio Di Studi Rurali SISMONDI, Pisa, Italy

Antisari LV, Orsini F, Marchetti L, Vianello G, Gianquinto G (2015) Heavy metal accumulation in vegetables grown in urban gardens. Agron Sustain Dev 35:1139-1147. doi:10.1007/s13593-015-0308-Z

Astee LY, Kishnani NT (2010) Building integrated agriculture: utilising rooftops for sustainable food crop cultivation in Singapore. J Green Build 5:105-113. doi:10.3992/jgb.5.2.105

Bohn K, Viljoen A (2010) The edible city: envisioning the continuous productive urban landscape (CPUL). J Archit 4:149-161

Caplow T (2009) Building integrated agriculture: philosophy and practice. In: Urban futures 2030. Visionen Künftigen Städtebaus und urbaner Lebensweisen, Berlin, pp 48-51
Cerón-Palma I, Sanyé-Mengual E, Oliver-Solà J, Montero J, Rieradevall J (2012) Barriers and opportunities regarding the implementation of Rooftop Eco.Greenhouses (RTEG) in Mediterranean cities of Europe. J Urban Technol 19:87-103. doi:10.1080/10630732.2012.717685

De Wilt J, Dobbelaar T (2005) Agroparks: the concept, the response, the practice. Innovation Network, Utrecht, The Netherlands

De Zeeuw H, Van Veenhuizen R, Dubbeling M (2011) The role of urban agriculture in building resilient cities in developing countries. J Agric Sci 149:153-163. doi:10.1017/S0021859610001279

Despommier D (2010) The vertical farm: feeding the world in the 21st century. Thomas Dunne Books, New York

Eigenbrod C, Gruda N (2014) Urban vegetable for food security in cities. A review. Agron Sustain Dev 35:483-489. doi:10.1007/s13593014-0273-y

Food and Agriculture Organization of the United Nations (FAO) (2008) Urban agriculture for sustainable poverty alleviation and food security. Position Paper, FAO, Africa

Hamilton AJ, Burry K, Mok H, Barker SF, Grove JR, Williamson VG (2014) Give peas a chance? Urban agriculture in developing countries. A review. Agron Sustain Dev 34:45-73. doi:10.1007/s13593013-0155-8

Kaufman J, Bailkey M (2000) Farming inside cities: entrepreneurial urban agriculture in the United States. Lincoln Institute of Land Policy, Cambridge

Lohrberg F, Timpe A, editors (2012) COST action urban agriculture Europe: Documentation 1st Working Group meeting, Aachen 912/7/2012 / COST / chair of landscape architecture, RWTH Aachen University. Aachen. www.urbanagricultureeurope.la.rwthaachen.de/files/cost uae aachen.pdf. Accessed 30 November 2015

Lucke D (1995) Akzeptanz: Legitimität in der "Abstimmungsgesellschaft" [Acceptance: legitimation in the voting society]. Leske + Budrich, Opladen

McClintock N (2010) Why farm the city? Theorizing urban agriculture through a lens of metabolic rift. Camb J Reg Econ Soc 3:191-207

Mok H, Williamson VG, Grove JR, Burry K, Barker SF, Hamilton AJ (2014) Strawberry fields forever? Urban agriculture in developed countries: a review. Agron Sustain Dev 34:21-43. doi:10.1007/ s13593-013-0156-7

Mougeot LJA (2001) Urban agriculture: definition, presence, potentials and risks. In: Growing cities, growing food: urban agriculture on the policy agenda. Zentralstelle für Ernährung und Landwirtschaft, Feldafing, Germany, pp 1-42

Opitz I, Berges R, Piorr A, Krikser T (2015) Contributing to food security in urban areas: differences between urban agriculture and peri-urban agriculture in the global north. Agric Hum Values (Online First). doi: 10.1007/s10460-015-9610-2

Orsini F, Gasperi D, Marchetti L, Piovene C, Draghetti S, Ramazzotti S, Bazzocchi G, Gianquinto G (2014) Exploring the production capacity of rooftop gardens (RTGs) in urban agriculture: the potential impact on food and nutrition security, biodiversity and other ecosystem services in the city of Bologna. Food Sec 6:781-792. doi:10. 1007/s12571-014-0389-6

Orsini F, Kahane R, Nono-Womdim R, Gianquinto G (2013) Urban agriculture in the developing world: a review. Agron Sustain Dev 33: 695-720. doi:10.1007/s13593-013-0143-z

Poulsen M, Spiker M, Winch P (2014) Conceptualizing community buyin and its application to urban farming. J Agric Food Syst Community Dev 161-178. doi: 10.5304/jafscd.2014.051.014

Poulsen MN, McNab PR, Clayton ML, Neff RA (2015) A systematic review of urban agriculture and food security impacts in lowincome countries. Food Policy 55:131-146. doi:10.1016/j.foodpol. 2015.07.002

Pourias J, Aubry C, Duchemin E (2015) Is food a motivation for urban gardeners? Multifunctionality and the relative importance of the food function in urban collective gardens of Paris and Montreal. Agric Hum Values 1-17. doi: 10.1007/s10460-015-9606-y 
Sanyé-Mengual E (2015) Sustainability assessment of urban rooftop farming using an interdisciplinary approach. Dissertation. Institute of Environmental Science and Technology (ICTA) at Universitat Autònoma de Barcelona (UAB), Bellaterra, Spain

Sanyé-Mengual E, Cerón-Palma I, Oliver-Solà J, Montero JI, Rieradevall J (2013) Environmental analysis of the logistics of agricultural products from roof top greenhouses in Mediterranean urban areas. J Sci Food Agric 93:100-109. doi:10.1002/jsfa.5736

Sanyé-Mengual E, Oliver-Solà J, Montero JI, Rieradevall J (2015a) An environmental and economic life cycle assessment of Rooftop Greenhouse (RTG) implementation in Barcelona, Spain. Assessing new forms of urban agriculture from the greenhouse structure to the final product level. Int J Life Cycle Assess. doi:10.1007/s11367014-0836-9

Sanyé-Mengual E, Orsini F, Oliver-Solà J, Rieradevall J, Montero JI, Gianquinto G (2015b) Techniques and crops for efficient community rooftop gardens in Bologna (Italy). Agron Sustain Dev. doi:10. 1007/s13593-015-0331-0

Sanyé-Mengual E, Anguelovski I, Oliver-Solà J, Montero JI, Rieradevall $\mathrm{J}(2015 \mathrm{c})$ Resolving differing stakeholder perceptions of urban rooftop farming in Mediterranean cities: promoting food production as a driver for innovative forms of urban agriculture. Agric Hum Values 1-20. doi: 10.1007/s10460-015-9594-y

Säumel I, Kotsyuk I, Hölscher M, Lenkereit C, Weber F, Kowarik I (2012) How healthy is urban horticulture in high traffic areas? Trace metal concentrations in vegetable crops from plantings within inner city neighbourhoods in Berlin, Germany. Environ Pollut 165: 124-132. doi:10.1016/j.envpol.2012.02.019

Schulz K, Weith T, Bokelmann W, Petzke N (2013) Urbane Landwirtschaft und Green Production als Teil eines nachhaltigen Landmanagements [Urban agriculture and green production for a sustainable land management]. Institute of Socio- Economics, Müncheberg, Germany

Specht K, Siebert R, Hartmann I, Freisinger UB, Sawicka M, Werner A, Thomaier S, Henckel D, Walk H, Dierich A (2014) Urban agriculture of the future: an overview of sustainability aspects of food production in and on buildings. Agric Hum Values 31:33-51. doi: 10.1007/s10460-013-9448-4

Specht K, Siebert R, Thomaier S, Freisinger U, Sawicka M, Dierich A, Henckel D, Busse M (2015a) Zero-acreage farming in the city of Berlin: an aggregated stakeholder perspective on potential benefits and challenges. Sustainability 7:4511-4523. doi:10.3390/ su7044511

Specht K, Siebert R, Thomaier S (2015b) Perception and acceptance of agricultural production in and on urban buildings (ZFarming): a qualitative study from Berlin, Germany. Agric Hum Values 1-17. doi: $10.1007 / \mathrm{s} 10460-015-9658-\mathrm{z}$

Thiel M (2013) Grüne Gentechnik in Deutschland: Einstellungen der Bevölkerung [Green genetic engineering in Germany-the population's attitudes]. ibidem-Verlag, Stuttgart

Thomaier S, Specht K, Henckel D, Dierich A, Siebert R, Freisinger UB, Sawicka M (2015) Farming in and on urban buildings: present practice and specific novelties of zero-acreage farming (ZFarming). ReNew Agric Food Syst 30:43-54.doi:10.1017/ S1742170514000143
Torreggiani D, Dall'Ara E, Tassinari P (2012) The urban nature of agriculture: bidirectional trends between city and countryside. Cities 29: 412-416. doi:10.1016/j.cities.2011.12.006

van der Schans JW (2015) Business models urban agriculture. Wageningen UR

Yin RK (2009) Case study research: design and methods. Sage Publications, Los Angeles, CA

\section{Weblinks}

\#1: Allotment gardens. Data and facts. http://www.stadtentwicklung. berlin.de/umwelt/stadtgruen/kleingaerten/en/daten fakten/index. shtml, Senate Department for Urban Development and the Environment Berlin, accessed 17 December 2015

\#2: Himmelbeet. http://himmelbeet.de/, accessed 17 December 2015

\#3:Prinzessinengarten. http://prinzessinnengarten.net/, accessed 17 December 2015

\#4: Allmende Kontor. http://www.allmende-kontor.de/, accessed 17 December 2015

\#5: Meine Ernte. http://www.meine-ernte.de/, accessed 17 December 2015

\#6: Bauerngarten. http://www.bauerngarten.net/, accessed 17 December 2015

\#7: Speisegut. http://www.speisegut.com/, accessed 17 December 2015

\#8: Ökobarometer 2013 (Organic food survey). http://www.bmel.de/ SharedDocs/Downloads/Ernaehrung/Oekobarometer 2013.html, BMELV (German ministry of food, agriculture and consumer protection), accessed 17 December 2015

\#9: ECF Farmsystems GmbH. http://www.ecf-farmsystems.com/, accessed 17 December 2015

\#10: topfarmers. http://www.topfarmers.de/, accessed 17 December 2015

\#11: Tomatenfisch. http://www.tomatenfisch.igb-berlin.de/, accessed 17 December 2015

\#12: Watergy. http://www.watergy.de/, accessed 17 December 2015

\#13: Berlin Environmental Atlas 06.03 Open-Space Development (Edition 2006). http://www.stadtentwicklung.berlin.de/umwelt/ umweltatlas/eda603 01.htm, Senate Department for Urban Development and the Environment Berlin, accessed 17 December 2015

\#14: Urban, kompakt, durchgrünt" - Strategien für eine nachhaltige Stadtentwicklung. ("Urban, compact, green" - Strategies for sustainable urban development). http://www.umweltbundesamt.de/ sites/default/files/medien/378/dokumente/urban-kompakt durchgruent penn-bressel.pdf, UBA (Umweltbundesamt), accessed 17 December 2015

\#15: Naturstudie 2013 (Survey on nature perception 2013). https://www. bfn.de/0309 naturbewusstsein.html; BMUB/BfN, accessed 17 December 2015 